Article

\title{
Utilization of Carob Fruit as Sources of Phenolic Compounds with Antioxidant Potential: Extraction Optimization and Application in Food Models
}

\author{
Vlasios Goulas *(D) and Eva Georgiou \\ Department of Agricultural Sciences, Biotechnology and Food Science, Cyprus University of Technology, \\ Lemesos 3603, Cyprus; evg.georgiou@edu.cut.ac.cy \\ * Correspondence: vlasios.goulas@cut.ac.cy; Tel.: +357-2500-2141
}

Received: 17 November 2019; Accepted: 20 December 2019; Published: 24 December 2019

\begin{abstract}
The goal of this study was to explore the potential of carob extracts to act as lipid inhibitors in model food systems. First, the extraction efficacy of fourteen solvents on the phenolic and flavonoid contents as well as on the antioxidant activity was assessed. Results showed that the phenolic composition and antioxidant activity of the extracts were strongly affected by solvents. Subsequently, the antioxidant potential of the most promising extracts (water, methanol, acidic acetone, and acetone-water) against four model food systems were evaluated. The acidic acetone extract had the highest antioxidant activity $(70.3 \pm 5.3 \%)$ in the $\beta$-carotene-linoleic acid system, followed by the acetone-water extract $(62.1 \pm 4.9 \%)$. Both extracts significantly prevented the lipid oxidation in sunflower oil and cooked comminuted pork; the inhibition activity at the end of storage period was $36.7-50.5 \%$ and $17.4-24.8 \%$, respectively. A reduction of $49.5-54.8 \%$ in the formation of dienes in the oil-in-water emulsion was also found. The inhibitory effect of methanolic and aqueous extracts was significantly lower. Qualitative and quantitative variations in extracts are responsible for this antioxidant behavior in food systems. Gallic acid, myrecetin, rutin, and catechin are the main components of the extracts while myricetin and quercetin play an essential role in the antioxidant activity, according to the biochromatograms.
\end{abstract}

Keywords: antioxidant activity; carob; Ceratonia siliqua L.; emulsion; HPLC-DPPH; lipid oxidation; polyphenols; ultrasound assisted extraction

\section{Introduction}

Oxidation is one of the major causes of quality deterioration in foods. Lipid oxidation induces significant loss in the nutritional value in lipid foods and emulsions, affecting their quality characteristics and safety. Therefore, the use of antioxidant additives such as butylated hydroxytoluene (E321), butylated hydroxyanisole (E320), tert-butylhydroquinone (E319), and propyl gallate (E310) to retard oxidation and peroxidation is a common practice for the food industry [1,2]. Although long-term toxicity studies have been performed for the safety of synthetic antioxidants, there is a public conviction that natural antioxidants are safer than their synthetic analogues. Thus, the food industry is seeking natural, safe, and low-cost antioxidant compounds or fractions to substitute synthetic additives [3]. In this challenge, natural sources such as plants, food by-products, and marina flora have been extensively studied.

The carob tree (Ceratonia siliqua L.) is mostly found in the Mediterranean Basin and is considered as an underutilized crop [4]. However, carob fruit is an essential reservoir of nutritional and pharmaceutical compounds. More specific, carob seeds are usually utilized for the production of carob bean gum (E410), which is used as thickener, stabilizer, or flavoring in the food industry and as an active 
ingredient or carrier molecule in pharmaceuticals [4]. Carob pulp, the main part of the fruit, is also rich in sugars $(48-56 \%)$, which are extracted to produce syrups and molasses. Carob pulp has been also recognized as an excellent source of bioactive fibers [5]. Thus, many patents have been registered for the manipulation of these components of carob fruit. In contrast, the phenolic fraction of carob fruit is relatively unexploited, although significant amounts of phenolic compounds are found in carob fruit (1.2-7.0\%), which is comparable to other well-known Mediterranean plant-based foods [6]. Furthermore, carob fruit contains a variety of bioactive phytochemicals from several classes [7]. In particular, carob phenolic compounds mostly comprise hydroxybenzoic acids, flavonols, flavan-3-ols, and gallotannins [4,8].

In the last decade, there have been some attempts to recover phenolic antioxidants from carob fruit using different extraction techniques and solvents [9-11]. In addition, researchers have attempted to utilize carob antioxidants to reduce lipid oxidation in cooked pork meat [12], Atlantic horse mackerel [13], and sunflower [14] as well as improve the antioxidant potential in durum wheat pasta [15] and milk beverages [16]. To the best of our knowledge, information about the phenolic composition and antioxidant potency of carob fruit is still obscure as there is no available comparative study on the effect of solvents in extracting phenolic compounds and antioxidant activity. Thus, the aim of the present work was to evaluate different solvent systems and two carob varieties for the extraction of phenolic antioxidants from carob fruit. Then, the antioxidant effect of selected extracts were tested in four food systems in the search for new antioxidants for the food industry. Finally, High Performance Liquid Chromatography (HPLC) coupled on a-pre column 1,1-diphenyl-2-picrylhydrazyl (DPPH) assay was performed to find out the most powerful antioxidant compounds in carob fruit extracts.

\section{Materials and Methods}

\subsection{Chemicals and Fruit Material}

(+)-Catechin, (-)-epicatechin, myricetin quercetin rutin, and syringic acid were obtained from Sigma-Aldrich (St Louis, MI, USA). Gallic acid, analytical reagents, and common solvents were provided by Scharlau (Barcelona, Spain).

Carob fruits (Ceratonia siliqua L., cvs 'Tilliria' and 'Koumbota') were harvested at the maturity stage from an experimental orchard (Avdimou, Limassol district, Cyprus; $34^{\circ} 41^{\prime} 15.4^{\prime \prime} \mathrm{N}, 32^{\circ} 45^{\prime} 34.8^{\prime \prime}$ E). The carob fruits were pulverized by the employment of an electric coffee grinder (Bestron AKM1405 150W, Bestron Nederland BV, s-Hertogenbosch, The Netherlands). The moisture contents of Tilliria' and 'Koumbota' carob fruits were $13.07 \pm 0.89 \%$ and $13.65 \pm 0.64 \%$, respectively, as measured by a moisture analyzer (Kern MLS-50-3, KERN \& Sohn GmbH, Balingen, Germany).

\subsection{Preparation of Carob Fruit Extracts}

The ultrasound-assisted extraction was applied for the extraction of phenolic antioxidants from carob fruit. Briefly, approximately $2.5 \mathrm{~g}$ of carob fruit were mixed with $25 \mathrm{~mL}$ of a single solvent or solvent system. Then, they were sonicated for $30 \mathrm{~min}$ at $30^{\circ} \mathrm{C}$ in an ultrasound bath (UCI-50, $35 \mathrm{KHz}$, Raypa-R. Espinar, S.L., Terrassa, Spain). Samples were further centrifuged at $4700 \times g, 20^{\circ} \mathrm{C}$ for $15 \mathrm{~min}$. The supernatants were kept at $-20^{\circ} \mathrm{C}$ until analysis. In this study, water, methanol, ethanol, acetone, ethyl acetate, acidic methanol (methanol + water $+\mathrm{HCl}, 80: 19: 1 ; v / v / v)$ ), acidic ethanol (ethanol+ water $+\mathrm{HCl}, 80: 19: 1 ; v / v / v)$, acidic acetone (acetone + water $+\mathrm{HCl}, 80: 19: 1 ; v / v / v)$, methanol/water $(80 \%$ and $50 \% v / v)$, ethanol/water $(80 \%$ and $50 \% v / v)$, and acetone/ water $(80 \%$ and $50 \% v / v)$ were used as extraction solvents.

For the determination of the antioxidant properties of extracts in model food systems, an amount of $15 \mathrm{~g}$ of carob fruit was extracted with $150 \mathrm{~mL}$ of an appropriate solvent or system solvent as described above. Finally, the solvents were removed using a rotary evaporator and freeze-dryer to obtain the dry extract. 


\subsection{Total Phenolic Content by High-Throughput Folin-Ciocalteu Assay}

A microplate Folin-Ciocalteu assay was employed for the determination of the total phenolic content in carob fruit extracts [17]. More specifically, $50 \mu \mathrm{L}$ of diluted extracts were mixed with $50 \mu \mathrm{L}$ of Folin-Ciocalteu reagent $(1: 5, v / v)$ and $100 \mu \mathrm{L}$ of sodium hydroxide solution $\left(0.35 \mathrm{~mol} \cdot \mathrm{L}^{-1}\right)$ in each well. After a period of $3 \mathrm{~min}$, the absorbance of each sample was monitored at $760 \mathrm{~nm}$. A standard curve of gallic acid was prepared and results expressed as mg gallic acid equivalents (GAE) $100 \mathrm{~g}^{-1}$ carob fruit.

\subsection{Total Flavonoids by High-Throughput Technique}

The determination of total flavonoids was carried out by mixing $100 \mu \mathrm{L}$ distilled water, $10 \mu \mathrm{L}$ of $50 \mathrm{~g} \cdot \mathrm{L}^{-1} \mathrm{NaNO}_{2}$, and $25 \mu \mathrm{L}$ of the sample or standard solution. After $5 \mathrm{~min}, 15 \mu \mathrm{L}$ of $100 \mathrm{~g} \cdot \mathrm{L}^{-1} \mathrm{AlCl}_{3}$ was added to the mixture. Finally, aliquots of $50 \mu \mathrm{L}$ of sodium hydroxide solution $\left(1 \mathrm{~mol} \cdot \mathrm{L}^{-1}\right)$ and 50 $\mu \mathrm{L}$ of distilled water were added after $6 \mathrm{~min}$. The mixture was shaken for $30 \mathrm{~s}$ in the plate reader prior to absorbance measurements at $510 \mathrm{~nm}$ [18]. A standard curve of catechin hydrate was prepared and the results expressed as mg catechin equivalents (CE) $100 \mathrm{~g}^{-1}$ carob fruit.

\subsection{Antioxidant Activity by DPPH and Ferric Reducing Antioxidant Power (FRAP) High-Throughput Techniques}

The 1,1-diphenyl-2-picrylhydrazyl (DPPH) assay measures the scavenging activity of antioxidants against colorful radicals of DPPH. The reaction mixtures consisted of $75 \mu \mathrm{L}$ of extracts and $150 \mu \mathrm{L}$ DPPH methanolic solution $(0.2 \mathrm{mM})$. The mixtures were incubated for $30 \mathrm{~min}$; then, the absorbance was read at $515 \mathrm{~nm}$. Different concentrations of extracts were used for the determination and the antioxidant activity was expressed as $\mathrm{EC}_{50}$, plotting percent antioxidant activity against extract concentration [19].

The FRAP measurements were achieved by reacting $20 \mu \mathrm{L}$ of the sample or standard compound with $180 \mu \mathrm{L}$ FRAP solution (300 mM acetate buffer at pH 3.6, $10 \mathrm{mM}$ 2,4,6-Tris(2-pyridyl)-s-triazine solution, and $20 \mathrm{mM}$ ferric chloride solution in the ratio of 10:1:1,v/v/v) in 96-well plates. The reaction mixtures in well plates were allowed for $6 \mathrm{~min}$ at $37{ }^{\circ} \mathrm{C}$ and the absorbance was read at $595 \mathrm{~nm}$. A standard curve of iron sulfate $\left(\mathrm{FeSO}_{4}\right)$ was prepared and results expressed as $\mu \mathrm{mol} \mathrm{FeSO} 4100 \mathrm{~g}^{-1}$ carob fruit [20].

\subsection{Antioxidant Effect of Carob Fruit Extracts in $\beta$-Carotene-Linoleate Model System}

This protocol is based on the ability of the extracts to prevent the oxidative bleaching of colorful $\beta$-carotene in an emulsion. As described by Chandrasekara and Shahidi (2011), the carotene solution was prepared by dissolving $10 \mathrm{mg} \beta$-carotene in $10 \mathrm{~mL}$ of chloroform [21]. Then, $0.5 \mathrm{~mL}$ of the solution was transferred into a $50 \mathrm{~mL}$ round bottom flask and the solvent was removed with the employment of a rotary evaporator at $30^{\circ} \mathrm{C}$. After that, $20 \mathrm{mg}$ of linoleic acid, $200 \mathrm{mg}$ of Tween 20, and $50 \mathrm{~mL}$ of deionized water were mixed with vigorous shaking. In order to determine the $\beta$-carotene bleaching activity of the extract, $200 \mu \mathrm{L}$ of emulsion were mixed with $20 \mu \mathrm{L}$ of extracts in each well. The microplate was incubated at $45^{\circ} \mathrm{C}$ and absorbance was monitored at $450 \mathrm{~nm}$ after $60 \mathrm{~min}$. Gallic acid and catechin were also used as positive controls. The antioxidant activity was expressed as the percent inhibition relative to the control.

\subsection{Antioxidant Effect of Carob Fruit Extracts in Sunflower Oil}

Sunflower oil was enriched with carob extracts or pure compounds (control, 200 ppm carob fruit extracts, 200 ppm gallic acid, 200 ppm catechin). Five $\mathrm{mL}$ of the oil samples were transferred in $10 \mathrm{~mL}$ centrifuge vials and incubated at $60^{\circ} \mathrm{C}$ in a shaker oven (Lab Companion SI-600R; Jeio Tech Inc., Seoul, Korea) for 10 days. After 0,1,3, 7, and 10 days, samples from each treatment were picked randomly to determine the thiobarbituric acid (TBA) value in triplicate. The TBA assay can measure secondary oxidation products of malonaldehyde [3]. More specifically, $200 \mathrm{mg}$ of the oil samples were dissolved in $25 \mathrm{~mL}$ of 1-butanol. Subsequently, $5 \mathrm{~mL}$ of this solution was reacted with $10 \mathrm{~mL}$ of the TBA reagent 
$(0.2 \%, w / v)$ and incubated for $2 \mathrm{~h}$ at $95^{\circ} \mathrm{C}$. After cooling, the absorbance was measured at $532 \mathrm{~nm}$ against a blank.

\subsection{Antioxidant Effect of Carob Fruit Extracts in Oil-in-Water Emulsion}

The antioxidative effect of extracts in a model food emulsion was performed according to previous work [22]. For the preparation of the emulsion, $5 \mathrm{~g}$ sunflower oil, $1 \mathrm{~g}$ Tween 20, and $50 \mathrm{~mL}$ of $20 \mathrm{mM}$ sodium acetate buffer ( $\mathrm{pH}$ 3.0) were homogenized with an Ultra-turrax (IKA ${ }^{\circledR}$ Werke GmbH \& Co.KG, Staufen, Germany) operated at $16,000 \times \mathrm{rpm}$. Then, the emulsions were fortified with carob extracts, gallic acid, and catechin at a final concentration of $200 \mathrm{mg} \cdot \mathrm{L}^{-1}$ in the emulsion. A control without any antioxidant was also prepared. The emulsions were further homogenized with an ultrasonic processor operated for $5 \mathrm{~min}$ in an ice bath. Each emulsion was transferred into a plastic tube, capped, and incubated at $60^{\circ} \mathrm{C}$. After $0,1,2$, and 3 days, samples from each treatment were picked randomly for the determination of the TBA value as described above.

\subsection{Antioxidant Effect of Carob Fruit Extracts in Pork Model System}

Ground pork was mixed with $20 \%(w / v)$ deionized water; carob fruit extracts as well as gallic acid and catechin were also added at the concentration of $300 \mathrm{mg} \cdot \mathrm{kg}^{-1}$. After homogenization, the samples were cooked at $80 \pm 2{ }^{\circ} \mathrm{C}$ for $40 \mathrm{~min}$ while stirring every $5 \mathrm{~min}$. After cooling to room temperature, the samples were stored at $4{ }^{\circ} \mathrm{C}$ for 15 days [21]. After $0,3,7,10$, and 15 days, samples from each treatment were drawn for the determination of the TBA value. More specific, $2 \mathrm{~g}$ of each sample was mixed with $5 \mathrm{~mL}$ trichloroacetic acid $(10 \% \mathrm{w} / \mathrm{v})$ and vortexed at high speed for $2 \mathrm{~min}$. Subsequently, $5 \mathrm{~mL}$ of TBA $(0.02 \mathrm{M})$ was added and vortexed for $30 \mathrm{~s}$. The samples were centrifuged at $3000 \times g$ for $10 \mathrm{~min}$ and the supernatants were heated in a boiling water bath for $45 \mathrm{~min}$, cooled to room temperature in an ice bath, and the absorbance read at $532 \mathrm{~nm}$.

\subsection{Identification and Quantification of Phenolic Compounds Using HPLC}

The chromatographic analysis was performed on a Waters HPLC system equipped with a vacuum degasser, binary pump, autosampler, thermostated column compartment, and dual $\lambda$ absorbance detector (Waters Corporation, Milford, Ireland). The data collection and analysis was carried out by Empower software 2. An aliquot of carob extract $(20 \mu \mathrm{L})$ was separated on a Waters Sherisorb ${ }^{\circledR}$ ODS $2(15 \mathrm{~cm} \times 4.6 \mathrm{~mm}, 5 \mu \mathrm{m})$ column with a flow rate at $0.5 \mathrm{~mL} \cdot \mathrm{min}^{-1}$. The elution system consisted of solvents $A\left(1 \mathrm{~mL} \cdot \mathrm{L}^{-1}\right.$ acetic acid in water) and B (methanol). In particular, a gradient elution was applied as per our previous work described for the quantification of phenolic compounds in carob pulp extracts [8]. The identification and quantification of individual phenolic compounds was performed using standard compounds. More specifically, gallic acid, syringic acid, myricetin, quercetin and rutin, $(+)$-catechin, and (-)-epicatechin were studied in the present work.

\subsection{HPLC Coupled on a Pre-Column DPPH Assay}

One $\mathrm{mL}$ of freshly prepared DPPH methanol solution $(13 \mathrm{mM})$ was mixed with $2 \mathrm{~mL}$ of carob extracts $\left(10 \mathrm{mg} \cdot \mathrm{mL}^{-1}\right)$. The mixture was allowed to react at $25^{\circ} \mathrm{C}$ in the dark for $30 \mathrm{~min}$. Then, $20 \mu \mathrm{L}$ of the mixture was injected into the HPLC and analyzed as described above. A blank control of carob extracts with the same volume of methanol was also analyzed [23].

\subsection{Statistical Analysis}

Software package SPSS v22.0 (SPSS Inc., Chicago, IL, USA) was used for the statistical analysis. The comparison of averages of each treatment was based on the analysis of variance (one-way ANOVA) according to Duncan's multiple range test at a 5\% significance level. 


\section{Results and Discussion}

\subsection{Effects of Solvent Systems and Carob Variety on Phenolic Composition and Antioxidant Activity}

The extraction of phenolic compounds from plant material is a well-studied research area; several extraction methods have been adopted for this purpose. More specifically, conventional methods such as solid-liquid and soxhlet extractions as well as modern methods such as microwave-assisted extraction, supercritical fluid extraction, and ultrasound-assisted extraction have been frequently used. Based on the literature, the ultrasound-assisted extraction is preferred for phenolics due to its simplicity and effectiveness [24,25]. Our previous study also demonstrated the increase in the yield of phenolics by using ultrasound irradiation [26]. This increase may be explained by enhancing the fragmentation process and promoting the release, diffusion, and dissolution of the components inside cells [24]. Taking into consideration that ultrasound assisted extraction does not require sophisticated equipment and can be transferred to large scale extraction, this method was selected in the present study.

Regarding the extraction system, the phenolics were recovered from plant matter using common alcohols (methanol, ethanol), acetone, diethyl ether, and ethyl acetate. However, the extraction of very polar phenolic acids cannot be achieved with the utilization of pure organic solvents, thus aqueous mixtures with alcohol and acetone are also recommended [27]. Furthermore, acidified organic solvents are used to improve the recovery of phenolics as they destroy cell membranes and dissolve some phenolics [28]. Although these recommendations can be a valuable guide for researchers, it is common sense that a solvent may be efficient on one plant and less efficient on another. Thus the efficiency of 14 solvent systems to extract phenolic antioxidants from carob fruit was studied through the determination of phenolic content, flavonoid content, DPPH, and FRAP assays.

The phenolic content of carob fruit extracts showed considerable variation as a function of the solvent systems used and ranged from $7.1 \pm 0.9 \mathrm{mg} \mathrm{GAE} 100 \mathrm{~g}^{-1}$ to $382.0 \pm 23.8 \mathrm{mg}$ GAE $100 \mathrm{~g}^{-1}$. Results showed that the most powerful solvents to recover phenolics from carob fruits were water, acetone/water (50/50\% v/v), acidic acetone, methanol and ethanol/water (50/50\% v/v). In contrast, the pure organic solvents (ethyl acetate and acetone) yielded extracts with the lowest phenolic contents (Table 1). These findings are also supported by the activity coefficients predicted using the Universal Functional Group Activity Coefficient (UNIFAC) model in our previous study, highlighting the solubilization preference of natural phenols to alcohols and acetone [29]. Furthermore, aqueous mixtures with solvents usually extract higher phenolic contents than pure solvents as water may swell the plant material and increase extractability [30]. Surprisingly, the highest phenolic content was found in the aqueous extract due to the abundance of phenolic acids and gallotannins in the phenolic fraction [4]. The results also disclosed that the phenolic content of the extracts were not influenced by carob variety $(p>0.7)$.

The total flavonoid content of the carob extracts was also strongly affected by the extraction system as they fluctuated between 0 and $98.7 \pm 2.4 \mathrm{mg} \mathrm{CE} 100 \mathrm{~g}^{-1}$. Results showed that the most suitable solvents for the recovery of carob flavonoids were acidic acetone and aqueous acetone mixtures. As many of the flavonoids occur in carob fruit as their glycoside derivatives, the use of acetone-water mixtures can be explained. On the other hand, the extracts of pure solvents (acetone, ethyl acetate, methanol, and ethanol) contained lower amounts of flavonoids. This means that the carob fruit comprises more glycosidic forms of flavonoids than aglycones. Indeed, the main flavonoids in carob fruit, namely quercetin, myricetin, and kaempferol, are found as glycosidic derivatives [31,32]. Finally, the comparison of carob varieties showed that the 'Tilliria' carob fruit was a slightly richer source of flavonoids than the 'Koumbota' carob fruit $(p=0.06)$. 
Table 1. Effect of extraction solvents on total phenolic content (TPC), total flavonoid content (TFC), and antioxidant activity of the carob extracts. Results are the means \pm standard error. Labelled with the same letter did not differ significantly $(p \leq 0.05)$ according to Duncan's test.

\begin{tabular}{|c|c|c|c|c|}
\hline Solvent System & $\begin{array}{c}\text { TPC } \\
\left(\mathrm{mg} \mathrm{GAE}^{\mathbf{1}} 100 \mathrm{~g}^{-1}\right)\end{array}$ & $\begin{array}{c}\text { TFC } \\
\left(m g \text { CE } 100 \mathrm{~g}^{-1}\right)\end{array}$ & $\begin{array}{c}\text { DPPH } \\
\mathrm{IC}_{50}^{3} \\
\left(\mathrm{mg} \mathrm{mL}^{-1}\right)\end{array}$ & $\begin{array}{c}\text { FRAP } \\
\left(\mathrm{mg} \mathrm{FeSO}_{4} \mathbf{1 0 0 ~ g}^{-1}\right)\end{array}$ \\
\hline \multicolumn{5}{|c|}{ 'Tilliria' Carob Fruit } \\
\hline $100 \%$ Water & $382.0 \pm 23.8^{a}$ & $22.9 \pm 0.3^{i, j}$ & $1.9 \pm 0.2^{f, g, h, i}$ & $339.7 \pm 4.0^{\mathrm{a}}$ \\
\hline $100 \%$ Methanol & $359.6 \pm 13.5^{\mathrm{a}, \mathrm{b}, \mathrm{c}}$ & $26.8 \pm 3.7 \mathrm{~h}, \mathrm{i}$ & $2.8 \pm 0.1^{\mathrm{e}, \mathrm{f}}$ & $338.7 \pm 39.3^{\mathrm{a}}$ \\
\hline $100 \%$ Ethanol & $145.7 \pm 19.0^{\mathrm{k}}$ & $8.7 \pm 0.1^{1, \mathrm{~m}}$ & $6.4 \pm 0.9^{b}$ & $296.4 \pm 19.8^{\mathrm{a}, \mathrm{b}, \mathrm{c}}$ \\
\hline $100 \%$ Acetone & $80.3 \pm 6.9^{1}$ & Not detected & $>20^{\mathrm{a}}$ & $98.8 \pm 5.5^{j}$ \\
\hline $100 \%$ Ethyl acetate & $7.1 \pm 0.9 \mathrm{~m}$ & $5.7 \pm 1.0^{\mathrm{m}, \mathrm{n}}$ & $>20^{a}$ & $29.2 \pm 4.1^{\mathrm{k}}$ \\
\hline Methanol + water $+\operatorname{HCl}(80: 19: 1, v / v / v)$ & $288.4 \pm 19.4^{\mathrm{h}}$ & $70.5 \pm 1.8^{c}$ & $1.6 \pm 0.2^{g, h, i}$ & $245.5 \pm 28.1^{\mathrm{c}, \mathrm{d}, \mathrm{e}, \mathrm{f}}$ \\
\hline Ethanol + water $+\mathrm{HCl}(80: 19: 1, v / v / v)$ & $315.8 \pm 6.7^{\mathrm{e}, \mathrm{f}, \mathrm{g}, \mathrm{h}}$ & $55.7 \pm 5.7^{\mathrm{d}, \mathrm{e}, \mathrm{f}}$ & $2.1 \pm 0.4^{\mathrm{e}, \mathrm{f}, \mathrm{g}, \mathrm{h}, \mathrm{i}}$ & $270.2 \pm 7.4^{b, c, d}$ \\
\hline Acetone + water $+\mathrm{HCl}(80: 19: 1, v / v / v)$ & $348.6 \pm 5.8^{\mathrm{a}, \mathrm{b}, \mathrm{c}, \mathrm{d}, \mathrm{e}}$ & $98.7 \pm 2.4^{\mathrm{a}}$ & $1.4 \pm 0.0^{\mathrm{h}, \mathrm{i}}$ & $271.6 \pm 29.1^{b, c, d}$ \\
\hline Methanol + water $(80: 20, v / v)$ & $342.2 \pm 9.4 \mathrm{~b}, \mathrm{c}, \mathrm{d}, \mathrm{e}$ & $49.3 \pm 1.4^{\mathrm{f}}$ & $2.2 \pm 0.5^{\mathrm{e}, \mathrm{f}, \mathrm{g}, \mathrm{h}, \mathrm{i}}$ & $205.7 \pm 8.9^{\mathrm{f}, \mathrm{e}, \mathrm{g}, \mathrm{h}}$ \\
\hline Methanol + water $(50: 50, v / v)$ & $362.0 \pm 5.9^{a, b}$ & $51.2 \pm 0.1^{\mathrm{f}}$ & $1.9 \pm 0.2^{\mathrm{e}, \mathrm{f}, \mathrm{g}, \mathrm{h}, \mathrm{i}}$ & $257.8^{ \pm} 31.8^{\mathrm{c}, \mathrm{d}, \mathrm{e}}$ \\
\hline Ethanol + water $(80: 20, v / v)$ & $304.2 \pm 3.4^{\mathrm{f}, \mathrm{g}, \mathrm{h}}$ & $22.7 \pm 2.7^{\mathrm{i}, \mathrm{j}}$ & $2.9 \pm 0.2^{\mathrm{e}, \mathrm{f}}$ & $335.6 \pm 0.6^{\mathrm{a}}$ \\
\hline Ethanol + water $(50: 50, v / v)$ & $323.9 \pm 3.0^{\mathrm{c}, \mathrm{d}, \mathrm{e}, \mathrm{f}, \mathrm{g}, \mathrm{h}}$ & $52.8 \pm 0.9^{\mathrm{e}, \mathrm{f}}$ & $2.1 \pm 0.3^{e, f, g, h, i}$ & $195.5 \pm 3.3^{\text {e.g,h }}$ \\
\hline Acetone + water $(80: 20, v / v)$ & $328.6 \pm 2.0^{b, c, d, e, f, g}$ & $88.6 \pm 9.0^{b}$ & $1.6 \pm 0.2^{\mathrm{i}}$ & $224.2 \pm 9.1 \mathrm{~d}, \mathrm{e}, \mathrm{f}, \mathrm{g}, \mathrm{h}$ \\
\hline Acetone + water $(50: 50, v / v)$ & $347.2 \pm 1.8^{\mathrm{a}, \mathrm{b}, \mathrm{c}, \mathrm{d}, \mathrm{e}}$ & $77.2 \pm 6.7^{c}$ & $1.4 \pm 0.1^{\mathrm{h}, \mathrm{i}}$ & $227.1 \pm 27.8^{\mathrm{d}, \mathrm{e}, \mathrm{f}, \mathrm{g}}$ \\
\hline \multicolumn{5}{|c|}{ 'Koumbota' Carob Fruit } \\
\hline $100 \%$ Water & $351.6 \pm 16.2^{\mathrm{a}, \mathrm{b}, \mathrm{c}, \mathrm{d}, \mathrm{e}}$ & $27.1 \pm 1.7^{\mathrm{h}, \mathrm{i}}$ & $2.0 \pm 0.4^{\mathrm{e}, \mathrm{f}, \mathrm{g}, \mathrm{h}, \mathrm{i}}$ & $324.1 \pm 37.1^{\mathrm{a}, \mathrm{b}}$ \\
\hline $100 \%$ Methanol & $323.0 \pm 10.3^{c, d, e, f, g, h}$ & $10.3 \pm 1.7^{\mathrm{l}, \mathrm{m}}$ & $2.4 \pm 0.2^{\mathrm{e}, \mathrm{g}}$ & $259.1 \pm 36.9^{\mathrm{c}, \mathrm{d}, \mathrm{e}}$ \\
\hline $100 \%$ Ethanol & $204.9 \pm 8.6^{\mathrm{j}}$ & $3.7 \pm 0.7 \mathrm{~m}, \mathrm{n}$ & $4.3 \pm 0.2^{c}$ & $209.9 \pm 37.7^{\mathrm{f}, \mathrm{e}, \mathrm{g}, \mathrm{h}}$ \\
\hline $100 \%$ Acetone & $57.9 \pm 3.5^{1}$ & $15.5 \pm 2.0^{\mathrm{j}, \mathrm{k}, \mathrm{l}}$ & $>20^{a}$ & $79.4 \pm 1.4^{\mathrm{j}, \mathrm{k}}$ \\
\hline $100 \%$ Ethyl acetate & $17.4 \pm 4.3^{\mathrm{m}}$ & $16.3 \pm 1.7^{\mathrm{j}, \mathrm{k}, \mathrm{l}}$ & $>20^{\mathrm{a}}$ & $41.1 \pm 6.5^{\mathrm{k}}$ \\
\hline Methanol + water $+\operatorname{HCl}(80: 19: 1, v / v / v)$ & $343.2 \pm 33.7^{\mathrm{b}, \mathrm{c}, \mathrm{d}, \mathrm{e}}$ & $38.8 \pm 3.0^{\mathrm{g}}$ & $1.8 \pm 0.2^{\mathrm{f}, \mathrm{g}, \mathrm{h}, \mathrm{i}}$ & $225.5 \pm 38.3^{\mathrm{d}, \mathrm{e}, \mathrm{f}, \mathrm{g}, \mathrm{h}}$ \\
\hline Ethanol + water+ $\mathrm{HCl}(80: 19: 1, v / v / v)$ & $320.8 \pm 28.6^{\mathrm{d}, \mathrm{e}, \mathrm{f}, \mathrm{g}, \mathrm{h}}$ & $33.4 \pm 4.8 \mathrm{~g}, \mathrm{~h}$ & $2.3 \pm 0.4^{\mathrm{e}, \mathrm{f}, \mathrm{g}, \mathrm{h}, \mathrm{i}}$ & $320.8 \pm 35.3^{a, b}$ \\
\hline Acetone + water $+\mathrm{HCl}(80: 19: 1, v / v / v)$ & $337.9 \pm 5.5^{\mathrm{b}, \mathrm{c}, \mathrm{d}, \mathrm{e}, \mathrm{f}}$ & $86.1 \pm 5.3^{b}$ & $1.5 \pm 0.1 \mathrm{~g}, \mathrm{~h}, \mathrm{i}$ & $223 \pm 22.8^{\mathrm{d}, \mathrm{e}, \mathrm{f}, \mathrm{g}, \mathrm{h}}$ \\
\hline Methanol + water $(80: 20, v / v)$ & $228.4 \pm 25.8^{\mathrm{i}, \mathrm{j}}$ & $20.8 \pm 1.6^{\mathrm{i}, \mathrm{j}, \mathrm{k}}$ & $3.0 \pm 0.4 \mathrm{~d}, \mathrm{e}$ & $170.3 \pm 10.4 \mathrm{~g}, \mathrm{~h}$ \\
\hline Methanol + water $(50: 50, v / v)$ & $293.2 \pm 32.0 \mathrm{~g}, \mathrm{~h}$ & $18.4 \pm 2.2^{\mathrm{j}, \mathrm{k}}$ & $2.6 \pm 0.1 \mathrm{e}, \mathrm{f}, \mathrm{g}, \mathrm{h}$ & $187.9 \pm 16.8^{\text {e,f,g,h }}$ \\
\hline Ethanol + water $(80: 20, v / v)$ & $255.0 \pm 20.0^{\mathrm{i}}$ & $13.9 \pm 1.5^{\mathrm{k}, \mathrm{l}}$ & $4.0 \pm 0.6^{\mathrm{c}, \mathrm{d}}$ & $281.8 \pm 28^{\mathrm{a}, \mathrm{b}, \mathrm{c}, \mathrm{d}}$ \\
\hline Ethanol + water $(50: 50, v / v)$ & $355.5 \pm 22.9^{\mathrm{a}, \mathrm{b}, \mathrm{c}, \mathrm{d}}$ & $32.1 \pm 3.2 \mathrm{~g}, \mathrm{~h}$ & $2.6 \pm 0.3^{\mathrm{e}, \mathrm{f}, \mathrm{g}, \mathrm{h}}$ & $167.0 \pm 3.1^{\mathrm{h}}$ \\
\hline Acetone + water $(80: 20, v / v)$ & $321.7 \pm 11.2^{\mathrm{c}, \mathrm{d}, \mathrm{e}, \mathrm{f}, \mathrm{g}, \mathrm{h}}$ & $59.4 \pm 3.2 \mathrm{~d}, \mathrm{e}$ & $1.5 \pm 0.0 \mathrm{~g}, \mathrm{~h}, \mathrm{i}$ & $188.2 \pm 24.6^{\mathrm{e}, \mathrm{f}, \mathrm{g}, \mathrm{h}}$ \\
\hline Acetone + water $(50: 50, v / v)$ & $351.4 \pm 4.1^{\mathrm{a}, \mathrm{b}, \mathrm{c}, \mathrm{d}, \mathrm{e}}$ & $62.56 \pm 6.1^{d}$ & $2.6 \pm 0.1^{e, f, g}$ & $325.5 \pm 27.7^{\mathrm{a}, \mathrm{b}}$ \\
\hline
\end{tabular}

GAE: gallic acid equivalents; CE: catechin equivalents; $\mathrm{EC}_{50}$ : the concentration of the extracts required for $50 \%$ of the antioxidant activity. The same letter in each column are not significantly different at $p \leq 0.05$, according to the Duncan's test. 
The efficacy of solvents on the antioxidant activity of the extracts was also studied with DPPH and FRAP assays. These assays are based on different mechanisms to evaluate the antioxidant activity of carob extracts. The DPPH assay measures the ability of antioxidants to scavenge free radicals, whereas the FRAP assay counts the ability of antioxidants to donate electrons to the yellow ferric tripyridyltriazine complex. Moreover, a correlation between these assays and anti-lipid oxidation has been found for plant extracts [33]. Both assays demonstrated that the ethyl acetate and acetone extracts had the lowest antioxidant activity compared to the extract obtained using other solvents. The DPPH assay revealed that the most promising solvents for the recovery of carob antioxidants were acetone-water $(80: 20, v / v)$, acidic acetone, acidic methanol, and water. Regarding the FRAP assay, the use of pure water, ethanol-water $(80: 20, v / v)$, methanol, and acidic ethanol were recommended in order to obtain carob extracts with high antioxidant activity. Differences between the antioxidant assays can be ascribed to the different mechanisms of measurement. Furthermore, the solvent had a significant effect on the estimated antioxidant activity as it determined the rates and mechanism of reaction of the phenolics with reagents [34]. Similarly to total phenolic content, both carob varieties presented equal antioxidant properties.

Based on our findings, four solvents were evaluated for their potential to act as antioxidants in food model systems. More specifically, two pure solvents and two solvent systems were selected due to their ability to recover antioxidant phenolics. Water, acidic acetone, and acetone-water $(80: 20, v / v)$ were the most appropriate solvents to produce carob extracts, which are rich in phenolic antioxidants. The main drawback of these solvents is the co-extraction of sugars that are found in high concentrations in carob fruit. Thus, the pure methanol was also tested in food models due to its superiority against other pure organic solvents. Regarding the varieties, 'Tilliria' carob fruit was used for the preparation of extracts for the incorporation in food systems, although, all assays showed no significant differences between the two varieties. However, the 'Tilliria' variety is the most widespread in Cyprus and its exploitation of a carob antioxidant could attract the interest of the food industry.

\subsection{Antioxidative Effect of Carob Extracts in Model Food Systems}

The most promising carob extracts were tested as antioxidant additives in four model food systems that describe the requirements of food industry. In addition, the antioxidant potential of carob extracts was compared with the antioxidant potential of pure gallic acid and catechin as they are well-known antioxidants and found in carob fruit. First, the antioxidant activity of carob extracts was assessed by the $\beta$-carotene-linoleic acid system. This assay is based on the discoloration of $\beta$-carotene as it is extremely susceptible to free-radical mediated oxidation. Thus, the oxidative degradation products of linoleic acid induce the discoloration of $\beta$-carotene. Figure 1 demonstrates the inhibitory activity of free radicals generated during the peroxidation of linoleic acid. Catechin better inhibits the formation of dienes than gallic acid, as previously reported by [35]. Among the carob extracts, the acidic acetone extract had the highest antioxidant activity $(70.3 \pm 5.3 \%)$ followed by the acetone-water extract $(62.1 \pm 4.9 \%)$ and aqueous $(52.4 \pm 4.4 \%)$ and methanolic $(50.1 \pm 3.9 \%)$ extracts. The antioxidant activity of extracts were comparable with the corresponding activity of the pure compounds, highlighting the presence of other antioxidant constituents. Based on previous studies, carob flavonols such as quercetin, myricetin, and their derivatives are strong inhibitors of the formation of dienes in the $\beta$-carotene-linoleic acid emulsion. Their activity is attributed to the presence of the double bond between C-2 and C-3 and a free hydroxyl in the C-3 position [36]. Therefore, a chromatographic study of carob extracts is expected to confirm this hypothesis. 


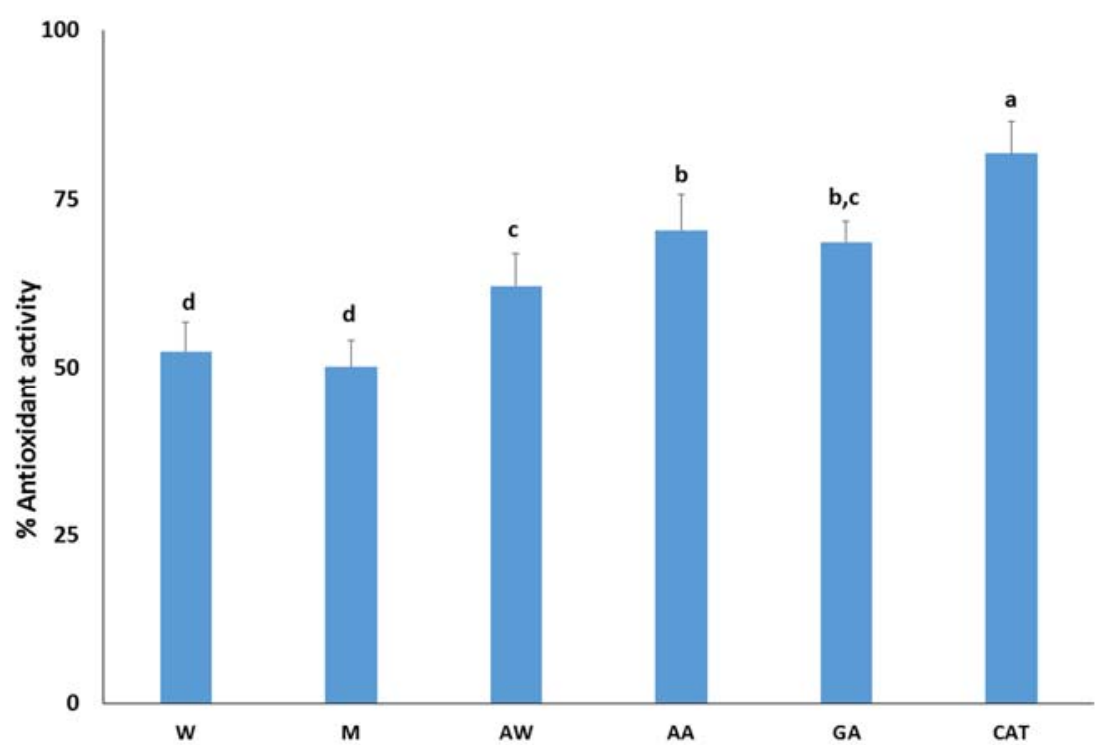

Figure 1. Antioxidant activity of carob extracts, gallic acid, and catechin in the $\beta$-carotene-linoleic acid system. The symbols W, M, AW, AA represent the water, methanol, acetone-water, and acidic acetone extracts; GA and CAT denote gallic acid and catechin, respectively. Means \pm standard error labelled with the same letter did not differ significantly $(p \leq 0.05)$ according to Duncan's test.

Next, the antioxidant efficiency of the carob extracts in sunflower oil in a water emulsion was determined. Figure 2 summarizes the effect of carob extracts on the inhibition of hydroperoxide formation in an oil in water emulsion during storage at $60^{\circ} \mathrm{C}$. After $24 \mathrm{~h}$, a substantial increase in the concentration of hydroperoxides was monitored for the control samples. Results show that the carob extracts were effective in preventing hydroperoxide formation emulsion, whereas significant differences were found among the extracts. Aqueous and methanolic extracts did not inhibit lipid oxidation. In contrast, acidic acetone and acetone-water extracts had potent antioxidant activity in the emulsion system and was comparable to the pure catechin. The antioxidant activity of both extracts was higher than pure gallic acid, highlighting their antioxidant potential. Furthermore, it is well-known that gallic acid is the main constituent of the phenolic fraction, therefore other potent phenolic compounds are responsible for the strong inhibitory effect of these extracts. A similar response of carob extracts in the formation of hydroperoxides in an emulsion was recorded after $48 \mathrm{~h}$ storage at $60^{\circ} \mathrm{C}$. Finally, the antioxidant activity of acidic acetone and acetone-water extracts was equal with the activity of pure gallic acid and weaker than that of pure catechin after a period of $72 \mathrm{~h}$. Overall, the acidic acetone and acetone-water extracts can be considered as antioxidative agents for sunflower oil in water emulsions.

Subsequently, the antioxidant activity of carob extracts was tested in an apolar medium such as sunflower oil. More specific, an amount of $200 \mathrm{ppm}$ of carob extracts was incorporated in sunflower oil and their ability to prevent lipid oxidation for a period of 10 days was assessed. The hyperoxide contents were increased with the progress of the storage period. In the first three days, all carob extracts inhibited lipid oxidation and their potential was equal to that of the pure compounds (Figure 3a). The most remarkable findings may be found at the end of the storage period. Carob extracts were classified based on the ability to prevent lipid oxidation. In particular, the acetone-water extract demonstrated the highest antioxidant activity, followed by acidic acetone, methanol, and water extracts. Although the antioxidant activity of carob extracts was weaker than the antioxidant activity of the pure compounds, they can be considered as efficient inhibitors of oxidation in sunflower oil. 


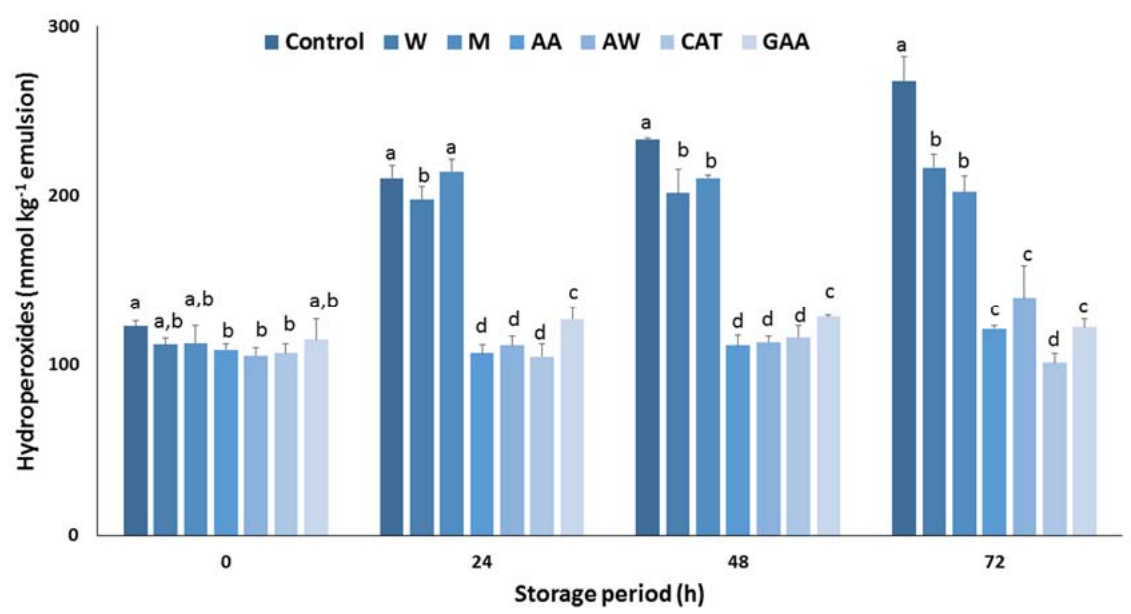

Figure 2. Antioxidant activity of carob extracts, gallic acid, and catechin in sunflower oil in water emulsion for $72 \mathrm{~h}$ at $60^{\circ} \mathrm{C}$. The symbols $\mathrm{W}, \mathrm{M}, \mathrm{AW}$, AA represent the water, methanol, acetone-water, and acidic acetone extracts; GA and CAT denote gallic acid and catechin, respectively. Means \pm standard error labelled with the same letter did not differ significantly $(p \leq 0.05)$ according to Duncan's test.

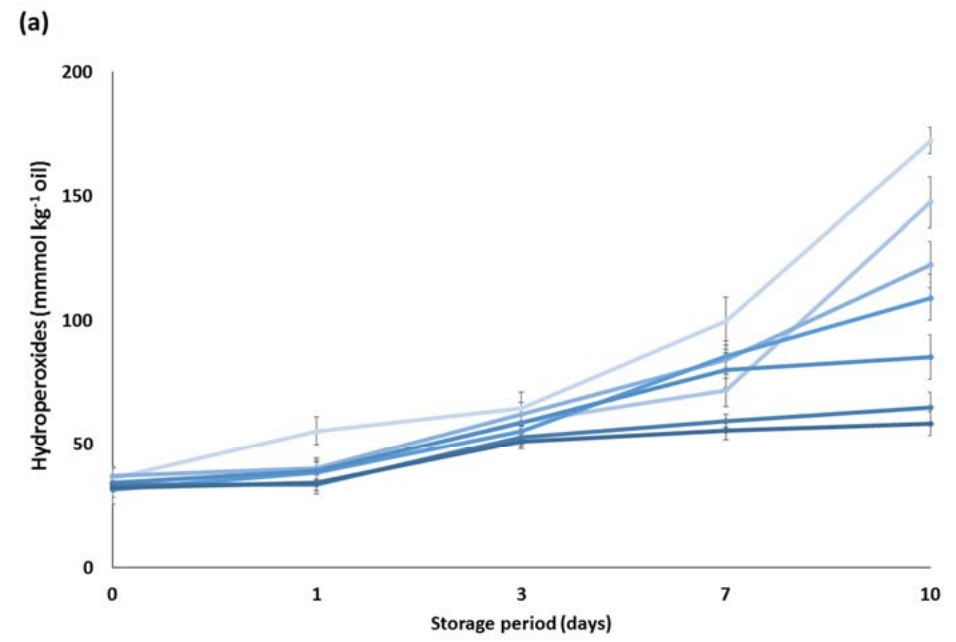

(b)

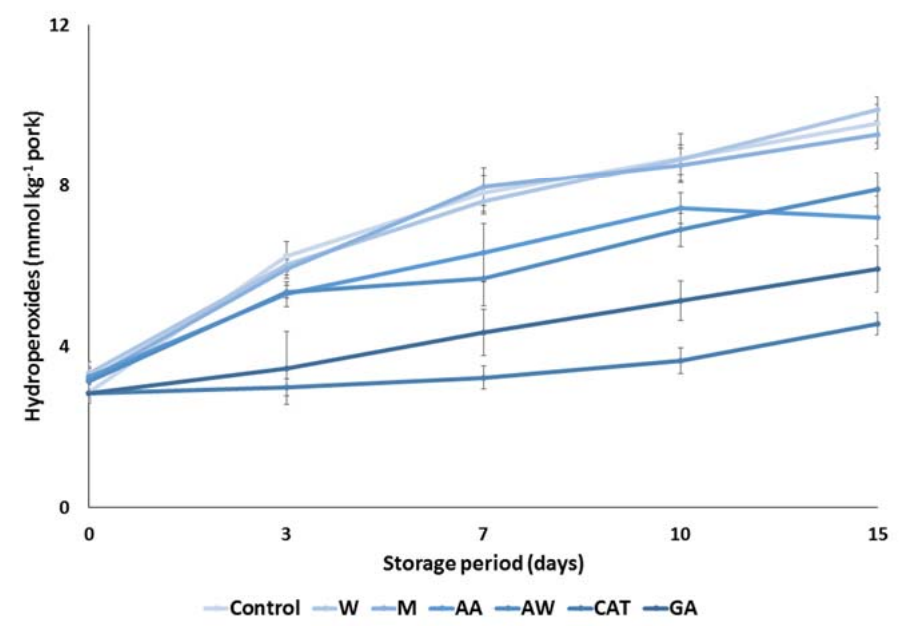

Figure 3. Antioxidant activity of the carob extracts, gallic acid, and catechin in (a) sunflower oil and (b) pork model system. The symbols W, M, AW, AA represent the water, methanol, acetone-water and acidic acetone extracts; GA and CAT denote gallic acid and catechin, respectively. 
The cooked comminuted pork model system was also used to determine the potential of carob extracts as antioxidative additives. Results demonstrated a gradual increase in the hydroperoxide contents in cooked pork during storage at $4{ }^{\circ} \mathrm{C}$ for 15 days. Figure $3 \mathrm{~b}$ clearly depicts a significant reduction in the formation of hydroperoxides when some carob extracts were added to the comminuted pork. More specifically, the acidic acetone and acetone-water extracts significantly inhibited the lipid oxidation during cold storage, although they were less potent than the pure compounds. The latter reduction is essential for food quality as lipid oxidation in muscle foods leads to the development of an off odor and off flavor in foods [21]. On the other hand, the aqueous and methanolic extract had no effect on the lipid oxidation of cooked pork. The different response of carob extracts in this food model is associated with the phenolic composition of carob extracts.

In conclusion, the utilization of different food model systems to evaluate the antioxidant activity of carob extracts revealed the most active extracts. The acidic acetone and acetone-water extracts significantly prevented the lipid oxidation in emulsions as well as in oil and pork. Thus, the study of the phenolic composition of extracts will allow us to understand the antioxidant behavior of extracts.

\subsection{Determination of Antioxidant Phenolic Constituents of Carob Extracts}

The carob extracts were subjected to HPLC analysis and the chromatograms revealed significant qualitative and quantitative differences among the studied extracts. More specifically, a reference HPLC fingerprint consisting of seven well-known phenolic antioxidants (gallic acid, syringic acid, catechin, epicatechin, quercetin, rutin, and myricetin) was developed to study the phenolic composition of the extracts. Figure 4 illustrates the phenolic composition of the carob extracts; the acidic acetone and acetone-water extracts are richer in phenolic compounds than that of the other two extracts. Gallic acid was the main phenolic compound in all extracts as its proportion to the phenolic content ranged from $63.7 \%$ to $74.6 \%$. The methanol and water extracts also contained significant amounts of rutin; its concentration was $216.8 \pm 15.6 \mu \mathrm{g} \cdot \mathrm{g}^{-1}$ and $505.4 \pm 18.0 \mu \mathrm{g} \cdot \mathrm{g}^{-1}$, respectively. Myricetin and catechin were found at high concentrations in the acidic acetone and acetone-water extracts. In addition, the recognized phenolic antioxidants, quercetin and catechin, were detected only in these two extracts. All of these differences may be explained their strong antioxidant activity in food model systems.

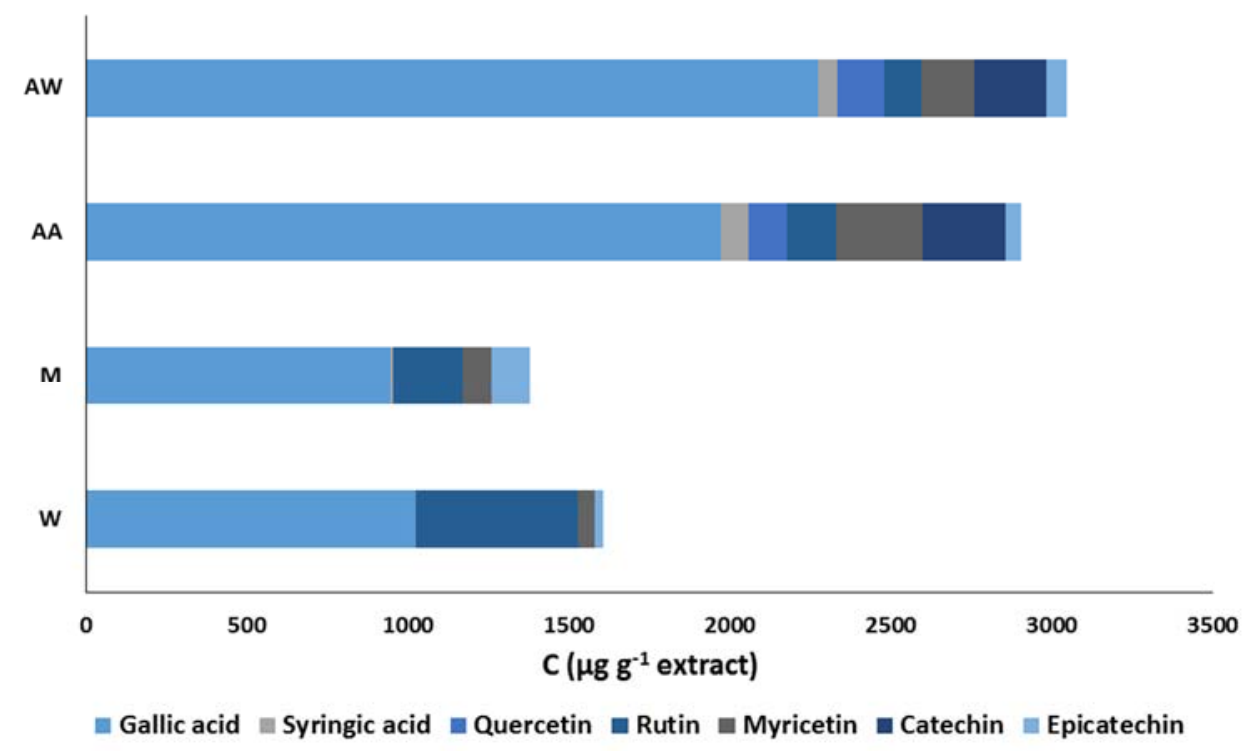

Figure 4. Comparison of the phenolic composition of carob extracts. The symbols W, M, AW, AA represent the water, methanol, acetone-water, and acidic acetone extracts, respectively.

In an attempt to decode the antioxidant activity of carob extracts, they were further analyzed with the use of HPLC coupled on a pre-column DPPH assay. The DPPH based antioxidant activity 
profile showed that several components decreased in the chromatogram of the reaction mixture of extracts and DPPH when compared to their original chromatograms. More specifically, the peak areas of all studied phenolic compounds significantly decreased after being reacted with the DPPH solution. The results showed that both flavonol aglycones, namely quercetin and myricentin, were the most potent antioxidant in carob extracts as they presented the highest rate of decrease (Table 2). Their presence only in the most active extracts could be responsible for their potent inhibitory effect in lipid oxidation. Gallic acid, the major component of extracts, also demonstrated a potent antioxidant potency as well as flavon-3-ols and rutin. Finally, a low contribution of syringic acid to the antioxidant activity of extracts was found according to the decreased rates of the peak areas. Our findings suggest that enrichment with quercetin and myricetin of carob extracts using fractionation and purification techniques is expected to further improve their antioxidant potential. Moreover, both flavonols have been recognized as potent lipid inhibitors [37,38].

Table 2. Decreased rate of peak areas in selected phenolic compounds in carob fruit extracts.

\begin{tabular}{cccccccc}
\hline & \multicolumn{2}{c}{ Hydroxybenzoic Acids } & \multicolumn{3}{c}{ Flavonols } & \multicolumn{2}{c}{ Flavan-3-ols } \\
\hline Extract & Gallic Acid & Syringic Acid & Quercetin & Rutin & Myricetin & Catechin & Epicatechin \\
\hline Water & 80.08 & nd * & nd & 67.09 & 94.53 & nd & 77.33 \\
Methanol & 78.29 & 67.16 & nd & 72.37 & 92.68 & nd & 70.58 \\
Acidic Acetone & 74.66 & 56.64 & 89.66 & 82.36 & 85.99 & 79.54 & 79.08 \\
Acetone Water & 71.89 & 51.25 & 88.91 & 80.55 & 87.33 & 77.63 & 76.44 \\
\hline
\end{tabular}

*nd: not detected.

\section{Conclusions}

The present work demonstrates that extraction solvents of different polarities yield carob extracts where the phenolic composition and antioxidant activity vary significantly. The present work provides a knowledge base for the selection of the most appropriate solvents to produce carob extracts for food applications. Based on these data, the potential of carob extracts to prevent lipid oxidation in food systems such as emulsions, sunflower oil, and cooked comminuted pork was explored and there are encouraging findings for the utilization of acidic acetone and acetone-water (50:50, $v / v)$ extracts as antioxidant agents by the food industry. The fractionation and purification of these extracts and encapsulation may be a perspective to improve their antioxidant activity in food systems.

Author Contributions: V.G. conceived the project, designed the experiments, interpreted the data, and wrote the manuscript; E.G. performed the experiments. All authors have read and agree to the published version of the manuscript.

Funding: This research was funded by the Cyprus University of Technology.

Acknowledgments: The authors would like to thank the Department of Agriculture of the Republic of Cyprus for kindly providing the carob fruits from the experimental orchard.

Conflicts of Interest: The authors declare no conflicts of interest.

\section{References}

1. Ngo, D.H.; Wijesekara, I.; Vo, T.S.; Van Ta, Q.; Kim, S.K. Marine Food-Derived Functional Ingredients as Potential Antioxidants in the Food Industry: An Overview. Food Res. Int. 2011, 44, 523-529. [CrossRef]

2. Taghvaei, M.; Jafari, S.M. Application and Stability of Natural Antioxidants in Edible Oils in Order to Substitute Synthetic Additives. J. Food Sci. Technol. 2015, 52, 1272-1282. [CrossRef] [PubMed]

3. Botsaris, G.; Orphanides, A.; Yiannakou, E.; Gekas, V.; Goulas, V. Antioxidant and Antimicrobial Effects of Pistacia Lentiscus L. Extracts in Pork Sausages. Food Technol. Biotechnol. 2015, 53. [CrossRef] [PubMed]

4. Goulas, V.; Stylos, E.; Chatziathanasiadou, M.V.; Mavromoustakos, T.; Tzakos, A.G. Functional Components of Carob Fruit: Linking the Chemical and Biological Space. Int. J. Mol. Sci. 2016, 17, 1875. [CrossRef]

5. Nasar-Abbas, S.M.; e-Huma, Z.; Vu, T.H.; Khan, M.K.; Esbenshade, H.; Jayasena, V. Carob Kibble: A Bioactive-Rich Food Ingredient. Compr. Rev. Food Sci. Food Saf. 2016, 15, 63-72. [CrossRef] 
6. Loullis, A.; Pinakoulaki, E. Carob as Cocoa Substitute: A Review on Composition, Health Benefits and Food Applications. Eur. Food Res. Technol. 2017, 244, 1-19. [CrossRef]

7. Owen, R.W.; Haubner, R.; Hull, W.E.; Erben, G.; Spiegelhalder, B.; Bartsch, H.; Haber, B. Isolation and Structure Elucidation of the Major Individual Polyphenols in Carob Fibre. Food Chem. Toxicol. 2003, 41, 1727-1738. [CrossRef]

8. Goulas, V.; Hadjisolomou, A. Dynamic Changes in Targeted Phenolic Compounds and Antioxidant Potency of Carob Fruit (Ceratonia Siliqua L.) Products during in Vitro Digestion. Lwt Food Sci. Technol. 2019, 101, 269-275. [CrossRef]

9. Cavdarova, M.; Makris, D.P. Extraction Kinetics of Phenolics from Carob (Ceratonia siliqua L.) Kibbles Using Environmentally Benign Solvents. Waste Biomass Valoriz. 2014, 5, 773-779. [CrossRef]

10. Bernardo-Gil, M.G.; Roque, R.; Roseiro, L.B.; Duarte, L.C.; Gírio, F.; Esteves, P. Supercritical Extraction of Carob Kibbles (Ceratonia siliqua L.). J. Supercrit. Fluids 2011, 59, 36-42. [CrossRef]

11. Roseiro, L.B.; Tavares, C.S.; Roseiro, J.C.; Rauter, A.P. Antioxidants from Aqueous Decoction of Carob Pods Biomass (Ceretonia siliqua L.): Optimisation Using Response Surface Methodology and Phenolic Profile by Capillary Electrophoresis. Ind. Crops Prod. 2013, 44, 119-126. [CrossRef]

12. Bastida, S.; Sánchez-Muniz, F.J.; Olivero, R.; Pérez-Olleros, L.; Ruiz-Roso, B.; Jiménez-Colmenero, F. Antioxidant Activity of Carob Fruit Extracts in Cooked Pork Meat Systems during Chilled and Frozen Storage. Food Chem. 2009, 116, 748-754. [CrossRef]

13. Albertos, I.; Jaime, I.; María Diez, A.; González-Arnaiz, L.; Rico, D. Carob Seed Peel as Natural Antioxidant in Minced and Refrigerated $\left(4^{\circ} \mathrm{C}\right)$ Atlantic Horse Mackerel (Trachurus trachurus). LWT - Food Sci. Technol. 2015, 64, 650-656. [CrossRef]

14. Zulim Botega, D.; Bastida, S.; Marmesat, S.; Pérez-Olleros, L.; Ruiz-Roso, B.; Sánchez-Muniz, F.J. Carob Fruit Polyphenols Reduce Tocopherol Loss, Triacylglycerol Polymerization and Oxidation in Heated Sunflower Oil. JAOCS J. Am. Oil Chem. Soc. 2009, 86, 419-425. [CrossRef]

15. Sęczyk, Ł.; Swieca, M.; Gawlik-Dziki, U. Effect of Carob (Ceratonia Siliqua L.) Flour on the Antioxidant Potential, Nutritional Quality, and Sensory Characteristics of Fortified Durum Wheat Pasta. Food Chem. 2016, 194, 637-642. [CrossRef]

16. Srour, N.; Daroub, H.; Toufeili, I.; Olabi, A. Developing a Carob-Based Milk Beverage Using Different Varieties of Carob Pods and Two Roasting Treatments and Assessing Their Effect on Quality Characteristics. J. Sci. Food Agric. 2016, 96, 3047-3057. [CrossRef]

17. Magalhães, L.M.; Santos, F.; Segundo, M.A.; Reis, S.; Lima, J.L.F.C. Rapid Microplate High-Throughput Methodology for Assessment of Folin-Ciocalteu Reducing Capacity. Talanta 2010, 83, 441-447. [CrossRef]

18. Herald, T.J.; Gadgil, P.; Tilley, M. High-Throughput Micro Plate Assays for Screening Flavonoid Content and DPPH-Scavenging Activity in Sorghum Bran and Flour. J. Sci. Food Agric. 2012, 92, 2326-2331. [CrossRef]

19. Nuengchamnong, N.; Krittasilp, K.; Ingkaninan, K. Rapid Screening and Identification of Antioxidants in Aqueous Extracts of Houttuynia cordata Using LC-ESI-MS Coupled with DPPH Assay. Food Chem. 2009, 117, 750-756. [CrossRef]

20. Huber, G.M.; Rupasinghe, H.P.V. Phenolic Profiles and Antioxidant Properties of Apple Skin Extracts. J. Food Sci. 2009, 74, 693-700. [CrossRef]

21. Chandrasekara, N.; Shahidi, F. Antioxidative Potential of Cashew Phenolics in Food and Biological Model Systems as Affected by Roasting. Food Chem. 2011, 129, 1388-1396. [CrossRef]

22. Ospina, M.; Montaña-Oviedo, K.; Díaz-Duque, Á.; Toloza-Daza, H.; Narváez-Cuenca, C.E. Utilization of Fruit Pomace, Overripe Fruit, and Bush Pruning Residues from Andes Berry (Rubus glaucus benth) as Antioxidants in an Oil in Water Emulsion. Food Chem. 2019, 281, 114-123. [CrossRef] [PubMed]

23. Zhang, C.; Shen, X.; Chen, J.; Jiang, X.; Hu, F.L. Identification of Free Radical Scavengers from Brazilian Green Propolis Using Off-Line HPLC-DPPH Assay and LC-MS. J. Food Sci. 2017, 82, 1602-1607. [CrossRef] [PubMed]

24. Zhong, L.; Yuan, Z.; Rong, L.; Zhang, Y.; Xiong, G.; Liu, Y.; Li, C. An Optimized Method for Extraction and Characterization of Phenolic Compounds in Dendranthema indicum var. aromaticum Flower. Sci. Rep. 2019, 9, 7745. [CrossRef] [PubMed]

25. Domínguez-Rodríguez, G.; Marina, M.L.; Plaza, M. Strategies for the Extraction and Analysis of Non-Extractable Polyphenols from Plants. J. Chromatogr. A 2017, 1514, 1-15. [CrossRef] [PubMed] 
26. Orphanides, A.; Goulas, V.; Gekas, V. Introducing the Concept of Sono-Chemical Potential: A Phenomenological Model for Ultrasound Assisted Extraction. J. Food Eng. 2014, 120, 191-196. [CrossRef]

27. Stalikas, C.D. Extraction, Separation, and Detection Methods for Phenolic Acids and Flavonoids. J. Sep. Sci. 2007, 30, 3268-3295. [CrossRef]

28. Garcia-Salas, P.; Morales-Soto, A.; Segura-Carretero, A.; Fernández-Gutiérrez, A. Phenolic-CompoundExtraction Systems for Fruit and Vegetable Samples. Molecules 2010, 15, 8813-8826. [CrossRef]

29. Galanakis, C.M.; Goulas, V.; Tsakona, S.; Manganaris, G.A.; Gekas, V. A Knowledge Base for the Recovery of Natural Phenols with Different Solvents. Int. J. Food Prop. 2013, 16, 382-396. [CrossRef]

30. Bhebhe, M.; Füller, T.N.; Chipurura, B.; Muchuweti, M. Effect of Solvent Type on Total Phenolic Content and Free Radical Scavenging Activity of Black Tea and Herbal Infusions. Food Anal. Methods 2016, 9, 1060-1067. [CrossRef]

31. Papagiannopoulos, M.; Wollseifen, H.R.; Mellenthin, A.; Haber, B.; Galensa, R. Identification and Quantification of Polyphenols in Carob Fruits (Ceratonia siliqua L.) and Derived Products by HPLC-UV-ESI/MSn. J. Agric. Food Chem. 2004, 52, 3784-3791. [CrossRef] [PubMed]

32. Rakib, E.M.; Chicha, H.; Abouricha, S.; Alaoui, M. Determination of Phenolic Composition of Carob Pods Grown in Different Regions of Morocco. J. Nat. Prod. 2010, 3, 134-140.

33. Schwarz, K.; Bertelsen, G.; Nissen, L.R.; Gardner, P.T.; Heinonen, M.I.; Hopia, A.; Huynh-Ba, T.; Lambelet, P.; McPhail, D.; Skibsted, L.H.; et al. Investigation of Plant Extracts for the Protection of Processed Foods against Lipid Oxidation. Comparison of Antioxidant Assays Based on Radical Scavenging, Lipid Oxidation and Analysis of the Principal Antioxidant Compounds. Eur. Food Res. Technol. 2001, 212, 319-328. [CrossRef]

34. Nenadis, N.; Tsimidou, M. Observations on the Estimation of Scavenging Activity of Phenolic Compounds Using Rapid 1,1-Diphenyl-2-Picrylhydrazyl (DPPH.) Tests. JAOCS J. Am. Oil Chem. Soc. 2002, 79, 1191-1195. [CrossRef]

35. Jia, Z.S.; Zhou, B.; Yang, L.; Wu, L.M.; Liu, Z.L. Antioxidant Synergism of Tea Polyphenols and $\alpha$-Tocopherol against Free Radical Induced Peroxidation of Linoleic Acid in Solution. J. Chem. Soc. Perkin Trans. 2 1998, 1, 911-915. [CrossRef]

36. Burda, S.; Oleszek, W. Antioxidant and Antiradical Activities of Flavonoids. J. Agric. Food Chem. 2001, 49, 2774-2779. [CrossRef] [PubMed]

37. Dangles, O.; Dufour, C.; Fargeix, G. Inhibition of lipid peroxidation by quercetin and quercetin derivatives: Antioxidant and Prooxidant Effects. J. Chem. Soc. Perkin Trans. 2000, 2, 1215-1222. [CrossRef]

38. Marinova, E.; Toneva, A.; Yanishlieva, N. Synergistic Antioxidant Effect of $\alpha$-Tocopherol and Myricetin on the Autoxidation of Triacylglycerols of Sunflower Oil. Food Chem. 2008, 106, 628-633. [CrossRef] 